\title{
68. FLUID PERMEABILITY OF OCEANIC BASALTS ${ }^{1}$
}

\author{
Douglas M. Johnson, Program in Geosciences, The University of Texas at Dallas, P.O. Box 688, Richardson, Texas ${ }^{2}$
}

\begin{abstract}
The liquid permeabilities have been determined for 10 basalt samples from DSDP Hole 418A. Fresh basalts have an average permeability of $5.2 \times 10^{-16} \mathrm{~cm}^{2}$, but the presence of secondary minerals has a substantial effect upon the permeabilities of altered basalts. Smectite clays infilling the pore spaces of the basalts decrease the specific permeability slightly, and samples with calcium carbonate veinlets had permeabilities that were 2 to 4 orders of magnitude greater than for fresh basalts. A positive correlation of decreasing permeability of fresh basalts with depth position in the drill hole corresponds closely with decreasing bulk porosity with depth.
\end{abstract}

\section{INTRODUCTION}

Geologic processes at depths within the oceanic crust are likely to be strongly dependent upon the presence and character of fluid that exists within the pore spaces and cracks of the solid rock. Although the mechanism of chemical alteration in basalts is not entirely understood, it is clear that a water-rich environment is required, and that variations in pore fluids will cause variations in alteration geochemistry (Krauskopf, 1967; Grim, 1968). Changes in fluid content and flow rate will also have an effect upon seismic velocities, as can the degree of alteration in the basalts (Biot, 1956, a, b; Christensen and Salisbury, 1975). The existence of pore fluids in the basaltic crust depends upon the specific permeability of the rock matrix, which in turn is a function of petrology and structural history.

There are little data available on the permeabilities of igneous rocks. The measurements are not simple, since the permeabilities of these rocks are very low, and extraordinary procedures are needed to make reasonably accurate measurements. Hence, until recently, there had been no published liquid permeability data for basaltic rocks (Johnson, 1977; Hamano, 1977). In the present study, the measurements were made using the standard constant-head flow-rate technique (Wyckoff et al., 1933; Heid et al., 1950), but done under very constant temperature and head pressure to minimize the measurement error.

The measurements of fluid permeability for a set of oceanic basalts are presented in this report. The samples were taken from the basalts drilled at DSDP Hole 418A in the North Atlantic Ocean, about 800 kilometers north of Puerto Rico at the southern end of the Bermuda Rise. The samples represent a range in the degree of alteration minerals present, from fresh rock to smectite and carbonate-rich breccias. The permeabilities were also

\footnotetext{
${ }^{1}$ Contribution No. 354, Program in Geosciences, The University of Texas at Dallas.

2 Present address: Geophysics Program, AK-50, University of Washington, Seattle, Washington.
}

determined for a series of fresh basalts that came from different depths in the hole, in an effort to correlate change in permeability with an observed linear decrease of porosity with increased depth.

\section{CONCEPTS AND EXPERIMENTAL METHOD}

Permeability has been determined for porous materials using a variety of methods, direct and indirect. Indirect methods use parameters that are easy to obtain and are empirically related to permeability. The methods typically use fluid conductance, as in the resistivity technique (Brace et al., 1968; Brace, 1977) or a porosity-permeability relationship, as in thin-section analyses (Schopper, 1966, 1967; Burdine, 1953). The accuracy of all the indirect methods depends upon the parameter measurement as well as the validity of the empirical relationship of the parameters to the permeability. The direct flow-through technique is an immediate result of the fundamental work of Darcy (1856), using what is now known as Darcy's Law, where the permeability $k$ can be written as

$$
k=\left(\frac{Q}{A T}\right)\left(\frac{\mu}{\rho g}\right)
$$

where $\mu$ is the viscosity, $\rho$ is the fluid density, $Q$ the volume of fluid passed, $A$ the sample cross-sectional area normal to the fluid flow direction, $T$ the elapsed time of the experiment, and $g$ the gravitational acceleration. The measurement consists of allowing pressurized fluid to pass through the medium, while observing the volume flux rate of the fluid.

The permeability of an igneous rock will depend upon several factors, of which the petrology and structural history of the material are most significant. Fluid will flow in the rock along microcracks that penetrate through the sample, and through interconnected pore spaces or vesicles that exist principally due to the petrologic history of the rock. The number of pore throats or channelways connecting the vesicles, the variations in their cross-sectional area, and their degree of tortuosity are the principal elements control- 
ling the pore-space permeability (Schopper, 1966, 1967). The microcracks exist primarily because of variations in the stress history of the rocks, and may be due to thermal contraction, differential tectonic stresses, or lattice site corrosion. The flow along the microcrack boundaries will be diminished as the cracks close under increasing confining pressure. Hence, for rocks in which the microcracks are a significant factor in the rock permeability, a pressure dependence of permeability is expected; this has been shown to be the case for granites (Brace et al., 1965, 1968). Pore space-related permeability should be less pressure dependent since a very high confining pressure is required to close spherical pores in a rock (Walsh, 1965, 1968; Abey, 1977).

Secondary effects upon the permeability come from the measurement process. The validity of Darcy's Law has been demonstrated for a diversity of porous materials (Darcy, 1856; Heid et al., 1950; Klinkenberg, 1941); but nonlinear flow can occur in granular materials or when the fluid or medium consists of multiple components (Raats, 1972; Kutilek, 1972). Irregularities in flow rate can occur when minute particles within the medium rotate and shift into pore throats or cracks, plugging up individual flow paths. This phenomenon can have significant effects with low permeability materials; as a preventive measure in this experiment, the fluid used was triple-filtered and then each sample was run three times with a $180^{\circ}$ rotation after each run to ensure the dislodging of any particulate matter in the sample.

Another significant factor is that permeability is a property of the porous material, and solely of that material, no matter what fluid is used in the experiment. It is important to understand, however, that a fluid can react with the material it flows through, thus effectively creating a new medium. The potential chemical interaction of fluid and rock must be understood before the permeability measurement is made, since it is quite possible to break down a rock completely by use of the wrong fluid, or to obtain permeability values that are misleading (Breston et al., 1945; Kutilek, 1972). For the present study, salt water identical to that found at the drilling site was used as the percolating fluid in an effort to guarantee the integrity of the rock and any alteration minerals present. Although the exact composition of the pore fluids at depth is unknown, salt water is the best approximation.

The experimental scheme is diagrammed in Figure 1. The basalt samples were in cylindrical form, $2.54 \mathrm{~cm}$ in diameter and $2.00 \mathrm{~cm}$ in length, with the cylinder ends polished flat. The sample was jacketed in a tight-fitting rubber tube, around which was wrapped thin $(0.3 \mathrm{~mm})$ wire. Care was taken not to flex the tube by wrapping, especially near the sample edges. The assembly was then mounted in the constant-head pressure permeameter (Heid et al., 1950), the top piece fitting to the head pressure port, the bottom to the catch reservoir (output) port. The temperature of the fluid was maintained at $25^{\circ} \pm 0.2^{\circ}$ by closed circulation of fluid in piping mounted around the fluid supply and sample. Head pressure was maintained to within $\pm 0.1 \%$. All parameters measured were made using guidelines established by the American Petroleum Institute (1956).

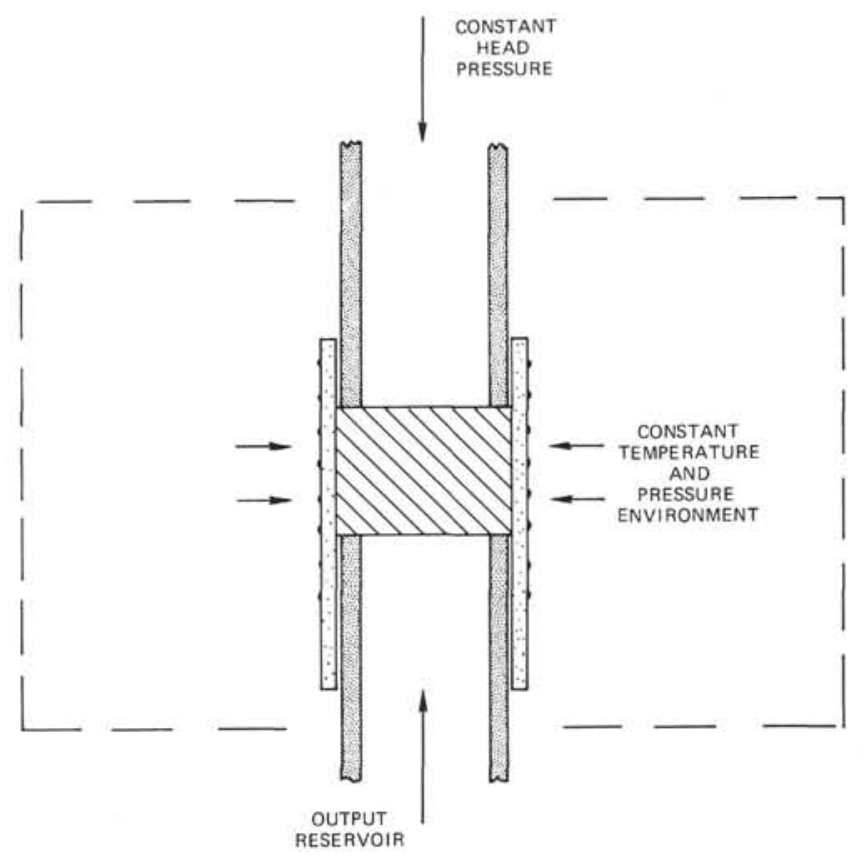

Figure 1. Flow scheme of the constant head permeameter.

The permeability data for the basalts measured are presented in Table 1. Values ranged from a low of $2.2 \times$ $10^{-13} \mathrm{~cm}^{2}$ for a breccia to $8.2 \times 10^{-17} \mathrm{~cm}^{2}$ for a smectiterich basalt. Estimated measurement error was $( \pm 0.8 \times$ $10^{-15} \mathrm{~cm}^{2}$ ) although measurement repeatability was better than half an order of magnitude at any value of permeability. The basalts used in the analysis were chosen for alteration content, degree of brecciation, and (for fresh basalts) depth position in the hole for a total sample count of 10 , with each sample run three times.

Fresh basalts were measured, with an average permeability of $5.2 \times 10^{-16} \mathrm{~cm}^{2}$. These values may be compared with those in Table 2 for consolidated and unconsolidated sediments, and for the few igneous rocks previously measured. Apparently, the mode of formation is more important than the petrology, since the granites have permeabilities comparable to the basalts, which are orders of magnitude less than those for sedimentary rocks. These low permeabilities can also be compared to those of fractured basalts measured in situ by Banks (1972), and to the calculated permeability from crack distributions (Johnson, this volume), both of which averaged about $10^{-4}$ to $10^{-5} \mathrm{~cm}^{2}$. Hence, relative to the fractured basalts, fresh solid basalt is almost impermeable.

A plot of permeability vs. depth position in the hole shows a slight decrease in permeability with depth (Figure 2 ). This corresponds to a similar phenomena observed in the porosity of the basalts drilled at Hole $418 \mathrm{~A}$, wherein porosity decreases linearly with depth, and bulk density increases accordingly (Figure 3 ). The linear decrease in porosity implies a continuous trend of pore closure in the basalts. At one atmosphere, there would be no difference in the porosities unless the rock at depth has undergone a long term compacting strain, causing permanent deformation of 
TABLE 1

Permeabilities and Physical Properties ${ }^{\mathrm{a}}$

\begin{tabular}{|c|c|c|c|c|c|c|c|}
\hline Run & $\begin{array}{c}\text { Sample } \\
\text { (Interval in } \mathrm{cm} \text { ) }\end{array}$ & Description of Sample & k & $\emptyset$ & $\rho_{\mathrm{b}}$ & $\rho_{\mathrm{g}}$ & $\mathrm{V}_{\mathrm{p}}$ \\
\hline 1 & $54-2,25$ & Fresh fine-grain basalt & $8.6 \times 10^{-16}$ & 2.84 & 2.94 & 3.00 & 5.92 \\
\hline 2 & $57-5,141$ & Fresh fine-grain basalt & $3.0 \times 10^{-16}$ & 4.40 & 2.86 & 2.95 & 5.66 \\
\hline 3 & $61-0, \mathrm{CC}$ & Fresh fine-grain basalt & $4.3 \times 10^{-16}$ & 2.84 & 2.92 & 2.97 & 5.69 \\
\hline 4 & $69-4,67$ & Fresh fine-grain basalt & $0.5 \times 10^{-16}$ & 4.35 & 2.88 & 2.96 & 5.85 \\
\hline 5 & $77-5,28$ & Fresh fine-grain basalt & $1.9 \times 10^{-16}$ & 2.01 & 2.92 & 2.96 & 5.98 \\
\hline 6 & 8507,86 & Fresh fine-grain basalt & $8.2 \times 10^{-17}$ & 2.24 & 2.95 & 2.99 & 5.96 \\
\hline 7 & $82-1,122$ & Coarse grain with smectite & $2.0 \times 10^{-16}$ & 1.68 & 2.96 & 2.99 & 5.78 \\
\hline 8 & $66-3,129$ & Smectite-filled basalt & $0.2 \times 10^{-17}$ & 6.36 & 2.80 & 2.93 & 5.28 \\
\hline 9 & $65-4,105$ & Basalt with $\mathrm{CaCO}_{3}$ veins & $6.1 \times 10^{-14}$ & 12.3 & 2.68 & 2.91 & 4.50 \\
\hline 10 & $75-5,46$ & Breccia with $\mathrm{CaCO}_{3}$ & $3.2 \times 10^{-13}$ & 14.6 & 2.52 & 2.78 & 4.00 \\
\hline
\end{tabular}

${ }^{\mathrm{a}} \mathrm{k}$ is the permeability, $\emptyset$ the porosity, $\rho_{\mathrm{b}}$ the bulk density, $\rho_{\mathrm{g}}$ the grain density, and $\mathrm{V}_{\mathrm{p}}$ the compressional wave velocity. All values at zero confining pressure.

TABLE 2

Specific Permeabilities of Other Materials

\begin{tabular}{lll}
\hline \multicolumn{1}{c}{ Material } & \multicolumn{1}{c}{ Permeability } & \multicolumn{1}{c}{ Reference } \\
\hline Carbonate sed. & $10^{-12}$ to $10^{-10}$ & Robertson (1967) \\
Clay sediments & $10^{-15}$ to $10^{-13}$ & Robertson (1967) \\
Sandstone berea & $1 \times 10^{-8}$ & Wyckoff et al. (1934) \\
Limestone & 1 to $5 \times 10^{-16}$ & Brace et al. (1968) \\
Diabase & $4.6 \times 10^{-14}$ & Brace et al. (1968) \\
Granite & $8.0 \times 10^{-16}$ & Brace et al. (1968) \\
Basalt & $2.5 \times 10^{-16}$ & Johnson (1977) \\
\hline
\end{tabular}

the pore spaces in the form of partial closure. This permanent compaction of the pores and pore throats will decrease the permeability of the rock. However, since the overall porosity is not great, and the change in porosity is small, a strong effect would not be expected for these basalts.

The basalts with a large amount of calcium carbonate infilling had permeabilities that were higher than either the smectite-rich or fresh basalts. The specific permeability of calcium carbonate is about $10^{-11} \mathrm{~cm}^{2}$, dependent upon its form (Wyckoff et al., 1934). The permeability contrast between the carbonate and fresh basalt is great enough that carbonate veinlets within the sample can act as fluid conductors allowing the fluid to pass through the sample at higher volume flux rates than would be expected for fresh basalts. For a well "'marbled"' basalt, the equivalent model is that of a fresh basalt with an abundance of open hairline cracks penetrating the sample, resulting in permeabilities two or three orders of magnitude greater than that of a solid fresh basalt.

The presence of smectite clays in the basalts had an effect opposite to that of calcium carbonate. Basalt samples with smectite infilling had the lowest permeabilities measured (see Table 1). This at first is surprising since the specific permeability of smectite clays averages $10^{-11} \mathrm{~cm}^{2}$ (Robertson, 1967), several orders of magnitude greater than the fresh basalts. A reasonable explanation can be developed by noting that the average crystal dimensions for the smectites is less than $1.0 \mu \mathrm{m}$ (Grim, 1968), whereas the pore spaces are typically greater than $200 \mu \mathrm{m}$ for these basalts. Smectite infilling of these pore spaces and microcracks will diminish the cross-sectional area of the pore throats, thus decreasing the flux rate and causing the permeability to decrease.

\section{CONCLUSIONS}

Ten basalt samples were measured for liquid permeability using the constant head-pressure technique. Fresh basalts have permeabilities of $10^{-16} \mathrm{~cm}^{2}$, and the presence of alteration minerals has significant effects upon the values determined. Smectite clays decrease the permeability, while calcium carbonate infilling tends to increase it, resulting in a total permeability range of $10^{-14}$ to $10^{-17} \mathrm{~cm}^{2}$. This implies that the oceanic crust is water saturated to a depth of 500 meters within 250,000 years of formation. If formation permeabilities are higher due to the presence of cracks, saturation will occur even more rapidly. A slight decrease in the permeability of fresh basalts corresponding to a linear decrease in the porosity of the basalts with depth is attributed to permanent deformation caused by long-term compaction.

\section{ACKNOWLEDGMENTS}

The author benefited from discussions with Anton Hales and Matthew Salisbury. A. Hales and J. Carter reviewed the manuscript. P. Morris of Atlantic Richfield Research Production Center and J. White of Core Labs, Inc. gave generous assistance to this project. Support for this research came from the Program for Geosciences, The University of Texas at Dallas.

\section{REFERENCES}

American Petroleum Institute, 1956. Recommended practice for determining permeability of porous media, API RP 27, Dallas.

Abey, A.E., 1977. A model for predicting the hydrostatic loading and unloading relationship of porous materials containing various amounts of fluid, J. Geophys. Res., v. 82, p. 5418.

Banks, D.C., 1972. In-situ measurements of permeability in basalt. In Percolation through fissured rock: Internat. Soc. Rock. Mechanics Symp., Stuttgart, Proc., TL-A, p. 6.

Biot, M., 1956a. Theory of propagation of elastic waves in a fluid-saturated porous solid I. Low frequency range, $J$. Acoustical Soc. Am., v. 28, p. 168. , 1956b. Theory of propagation of elastic saves in a fluid-saturated porous solid. II. Higher frequency range, $J$. Acoustical Soc. Am., v. 28, p. 179. 


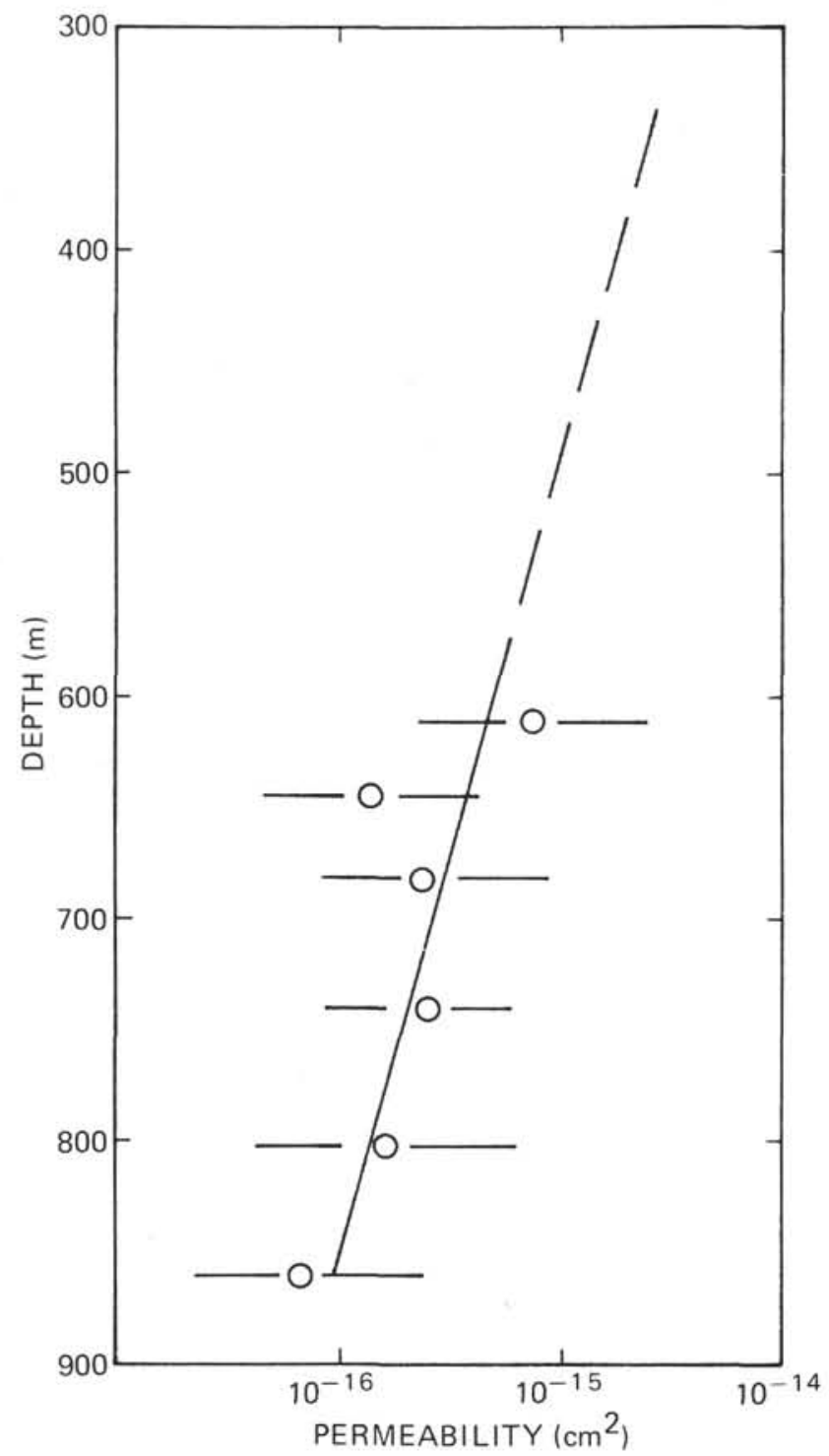

Figure 2. Permeability variation with depth for fresh basalts. The line passing through the points is handfitted, and the dashed portion is a projection to the surface of the basalt layer.

Brace, W.F., 1965. Some new measurements of linear compressibility of rocks, J. Geophys. Res., v. 70, p. 391. , 1977. Permeability from resistivity and pore shape, $J$. Geophys. Res., v. 82, p. 3343-3349.

Brace, W.F., Orange, A.S., and Madden, T.R., 1965. The effect of pressure on the electrical resistivity of water-saturated crystalline rocks, J. Geophys. Res., v. 70, p. 5669-5678.

Brace, W.F., Walsh, J.B., and Frangos, W.T., 1968. Permeability of granite under high pressure, J. of Geophys. Res., v. 73 , p. $2225-2236$.

Breston, J.N. and Johnson, W.E., 1945. Effect of $p \mathrm{H}$ on water intake rate of oil sands, Producers Monthly, v. 9, p. 19-23.

Burdine, N.T., 1953. Relative permeability calculations from pore size distribution data, Trans. AIME, v. 71, p. 198.

Christensen, N. and Salisbury, M., 1975. Structure and constitution of the lower oceanic crust, Rev. Geophys., v. 13, p. 57-86.

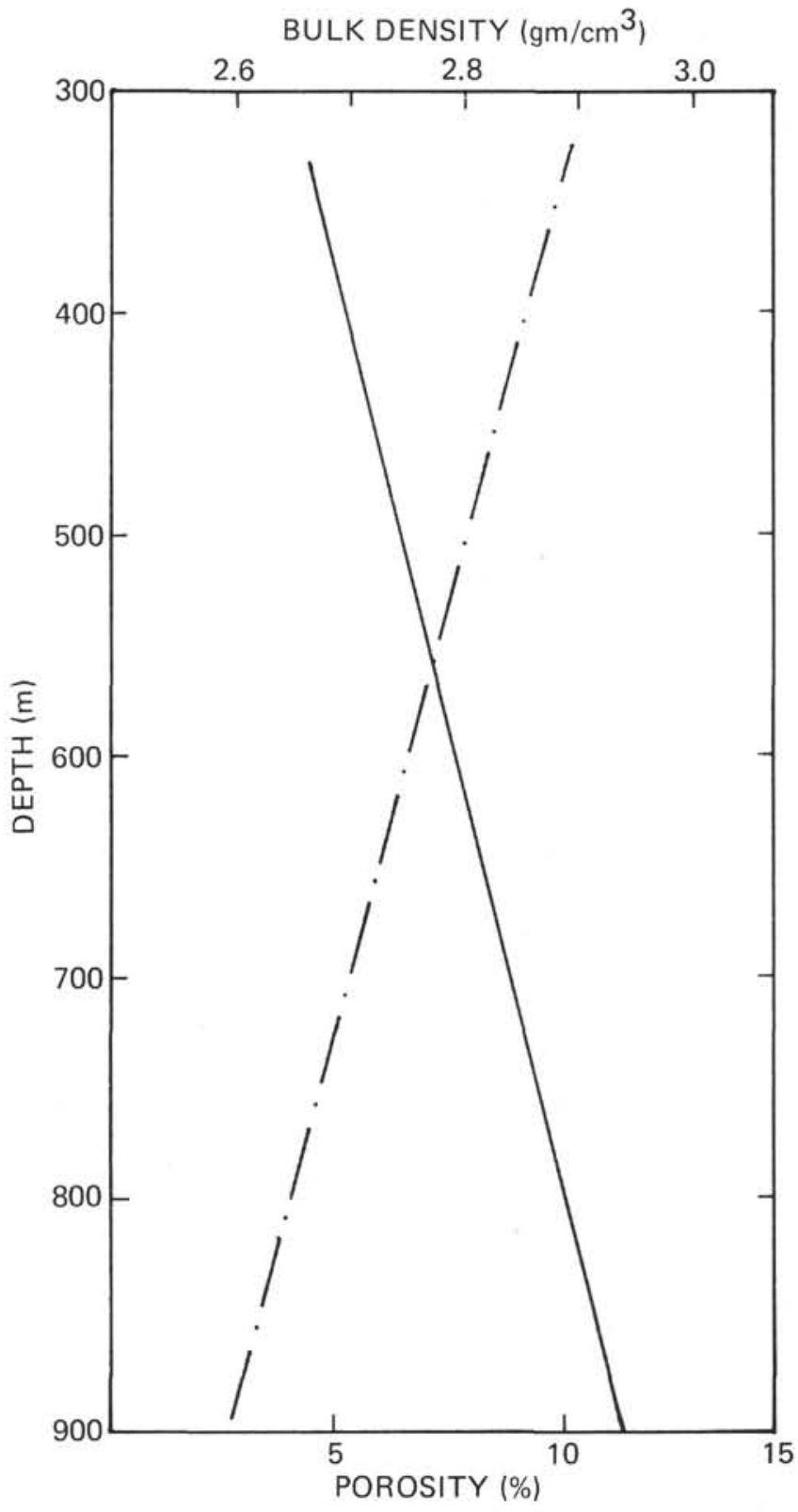

Figure 3. Least-squares fit of shipboard bulk density and porosity data, 156 data points for each parameter. Solid line is bulk density, dashed line is porosity.

Crane, K. and Normark, V., 1977. Hydrothermal activity and crestal structure of the East Pacific Rise at $21^{\circ} \mathrm{N}$., J. Geophys. Res., v. 82 , p. 5336.

Darcy, H., 1956. Les Fontaines Publiques de la Ville de Dijon: Paris (Victor Dalmont).

Grim, R.E., 1968. Clay mineralogy: New York, (McGraw-Hill).

Hamano, Y., 1977. The physical properties of basalts from Holes 417D and 418A (abstract), Eos. Trans. AGU, v. 58, p. 1174.

Heid, R., McMahon, J., Neilson, R., and Yuster, S., 1950. Study of the permeability of rocks to homogeneous fluids, Drilling and Production Practice, p. 230.

Johnson, D.M., 1977. Crack distribution and character in Layer 2 basalts (abstract), Eos. Trans. AGU, v. 58, p. 1174. 
Klinkenberg, L.J., 1941. The permeability of porous media to liquids and gases, Drilling and Production Practice, p. 200-233.

Krauskopf, K.B., 1967. Introduction to geochemistry: New York (McGraw-Hill).

Kutilek, M., 1972. Temperature and non-Darcian flow of water. In Fundamentals of transport phenomena in porous media: Amsterdam (Elsevier).

Raats, P.A.C., 1972. Non-Darcy flow in soils. In Fundamentals of transport phenomena in porous media: Amsterdam (Elsevier).

Robertson, E.C., 1967. Laboratory consolidation of carbonate sediment. In Richards, A. (Ed.), Marine geotechnique: Urbana (Univ. Illinois Press).
Schopper, J.R., 1966. A theoretical investigation on the formation factor/porosity relationship using a network model, Geophys. Prosp., v. 14, p. 301.

, 1967. A theoretical study on the reduction of statistical pore system parameters to measurable quantities, Geophys. Prosp., v. 15 , p. 262.

Walsh, J.B., 1965. The effect of cracks on the compressibility of rock, J. Geophys. Res., v. 70, p. 381-389.

Wyckoff, R.D., Botset, H.G., Muskat, M., and Reed, D.W., 1933. Measurement of the permeability of porous media for homogeneous fluids, Rev. Scientific Instruments, v. 4, p. $394-405$

1934. Measurement of permeability of porous media, Am. Assoc. Petrol. Geol., v. 18, p. 161-190. 